\title{
AVALIAÇÃO DAS CONDIÇÕES EXPERIMENTAIS DE CLAE NA DETERMINAÇÃO DE ÁCIDO FÓLICO EM LEITES ENRIQUECIDOS ${ }^{1}$
}

\author{
Rodrigo Ramos CATHARINO ${ }^{2, *}$, Jesuí Virgilio VISENTAINER ${ }^{3}$, Helena Teixeira GODOY ${ }^{2}$
}

\begin{abstract}
RESUMO
A importância que foi atribuída ao ácido fólico recentemente, em virtude de sua ação benéfica ao homem, tem aumentado o interesse dos pesquisadores por esta vitamina. Conseqüentemente, aumentou a preocupação dos analistas em desenvolver metodologias apropriadas para a determinação do ácido fólico (AF) em alimentos enriquecidos ou não com esta vitamina e o controle do mesmo em alimentos enriquecidos. Dentro desse panorama, o objetivo deste trabalho foi de avaliar algumas condições experimentais na determinação e no controle de ácido fólico, por cromatografia liquida de alta eficiência (CLAE), em leites enriquecidos. Utilizando coluna de fase reversa ( $\mathrm{C}_{18}$ ), foram testados 35 diferentes sistemas de eluição isocrática e 11 por gradiente. Os perfis cromatográficos foram monitorados em quatro diferentes comprimentos de onda. Foram realizados estudos sobre a estabilidade das soluções-padrão de AF utilizadas na quantificação. Em relação às etapas pré-cromatográficas, foram avaliadas 15 soluções extratoras. Os procedimentos de extração com soluções alcalinas, $\mathrm{pH}$ acima de 7.0, forneceram os melhores resultados. As melhores condições de análise foram obtidas com eluição por gradiente, a vazão de $0,5 \mathrm{~mL} / \mathrm{min}$, utilizando $10 \%$ de acetonitrila e $90 \%$ de fase aquosa tamponada (ácido acético $0,166 \mathrm{~mol} / \mathrm{L}$; hidróxido de potássio $0,01 \mathrm{~mol} / \mathrm{L} ; \mathrm{pH} 2,8)$ no início da corrida, fazendo um gradiente até oito minutos e meio $(8,5 \mathrm{~min}) \mathrm{chegando}$ em $24 \%$ de acetonitrila e $76 \%$ de fase aquosa tamponada, permanecendo esta concentração até nove minutos (9min) de corrida. A detecção do ácido fólico foi feita na região do ultra-violeta, a 290nm, em conseqüência da menor interferência dos constituintes da matriz. A quantificação foi feita por padronização externa, sendo que o padrão de ácido fólico, dissolvido em tampão fosfato $(\mathrm{pH} 6,5)$ e mantido a $4{ }^{\circ} \mathrm{C}$, pode ser utilizado por até 30 dias. Os limites de detecção e quantificação, determinados foram, respectivamente, 1,3ng/mL, 2,6ng/mL

Palavras-chave: ácido fólico; cromatografia liquida de alta eficiência; metodologia.
\end{abstract}

\section{SUMMARY}

EVALUATION OF THE EXPERIMENTAL CONDITIONS OF HPLC IN THE DETERMINATION OF FOLIC ACID IN ENRICHED MILK. The interest of researchers on this vitamin has increased because of the recent importance granted to folic acid, in view of its healthy action towards man, and consequently the concern of analysts to develop appropriate methodologies for folic acid determination and control in enriched or non-enriched foods. In this landscape, the objective of this research was to evaluate some experimental conditions in the determination of folic acid (FA), by high performance liquid chromatography (HPLC), in enriched milks. Using a reverse-phase column $\left(\mathrm{C}_{18}\right), 35$ different sujstenis isocratic and 11 gradient elution. Detection was at four different wavelengths. Studies were carried out about the stability of the FA standard solutions employed in the quantification. In relations a pre-chromatographic step, were available 15 solutions of extraction. The best results were obtained using an extraction procedure with alkaline solution, pH above of 7.0. The best conditions of analysis were obtained with gradient elution, flow rate of $0.5 \mathrm{~mL} / \mathrm{min}$, using $10 \%$ acetronitrile plus $90 \%$ buffer aqueous phase (acetic acid $0.166 \mathrm{~mol} / \mathrm{L}$; potassium hydroxide $0.01 \mathrm{~mol} / \mathrm{L}$; $\mathrm{pH} 2.8$ ) in the beginning, changing to $24 \%$ acetonitrile plus $76 \%$ buffer aqueous phase after 8.5 minutes, remaining this conditions until nine minutes (9.0min) of run. Detection of folic acid was obtained in the ultraviolet region, at 290nm, due to low presence of interfering substances from matrix. Quantification by means of an external standard curve. The folic acid standard dissolved in phosphate buffer ( $\mathrm{pH} 6.5$ ), under refrigeration (4 ${ }^{\circ} \mathrm{C}$ ), can to be used during 30 days. The limits of detection, quantification being respectively $1.3 \mathrm{ng} / \mathrm{mL} ; 2.6 \mathrm{ng} / \mathrm{mL}$.

Keywords: folic acid; high performance liquid chromatography; methodology.

\section{1 - INTRODUÇÃO}

O enriquecimento de alimentos com ácido fólico (AF) tem sido incentivado na última década devido, principalmente, a trabalhos que demonstraram uma possivel relação da vitamina com as doenças que acometem o tubo neural do feto, isto é, as malformações congênitas, que podem ser ocasionadas pela carência de ácido fólico na alimentação de gestantes [3, 7, 8, 9, 11, 17, 24]. Os produtos escolhidos para o enriquecimento com ácido fólico nos EUA são principalmente os cereais matinais, as farinhas e o macarrão, entre outros [2, 25]. No Brasil, o processo de enriquecimento de alimentos com AF vem incluindo uma ampla variedade de produtos, em especial os lácteos.

Recebido para publicação em 22/02/2002. Aceito para publicação em 27/02/2003 (000807)

2 Depto. Ciências de Alimentos-Fac. de Engenharia de Alimentos UNICAMP-SP-Brasil.CP-6121CEP-13083-970.E-mail: robit@bol.com.br ${ }^{3}$ Centro de Qímica - UEM-PR - Brasil.

* A quem a correspondência deve ser enviada.
A importância de métodos analíticos apropriados que garantam os niveis de enriquecimento nos produtos é uma preocupação, que deve ser encarada como fator essencial para oferecer a população as quantidades estipuladas nos rótulos dos produtos para beneficio comum de todos. Entretanto, a determinação de ácido fólico apresenta muitos desafios, mesmo com a utilização de técnicas sofisticadas, como é o caso da cromatografia liquida de alta eficiência, os quais incluem o melhoramento nos procedimentos de extração, limpeza e condições cromatográficas mais simples.

Há poucos trabalhos sobre o desenvolvimento de metodologias para análise de $\mathrm{AF}$ em produtos alimentícios [20, 21], a maioria das pesquisas foram conduzidas para a determinação de folatos [4, 12, 18, 19, 26, 28]. Geralmente no processo de extração é feita uma hidrólise alcalina, em virtude do aumento da estabilidade e solubilidade do ácido fólico, para romper os complexos protéicos, seguida de hidrólise enzimática para converter os folatos poliglutâmicos à forma monoglutâmica [4, 
20, 21, 28]. A extração, além de constituir uma das etapas mais importantes na determinação de ácido fólico em alimentos, é também a maior fonte de erro na determinação da vitamina [15]. Precipitação com ácido tricloroacético e técnicas de extração em fase sólida, tem sido utilizadas como procedimentos de limpeza dos extratos para a determinação de folatos [22].

As colunas cromatográficas mais utilizadas para a separação analitica de folatos são as de fase reversa, embora colunas de PLRSP (poliacrilamida estireno divinilbenzeno) e com grupamento fenil também foram empregadas por FINGLAS et al. [13] e LUCOCK et al. [19], respectivamente. As fases móveis empregadas na determinação de folatos não possuem grandes variações, sendo compostas basicamente de um modificador orgânico, metanol ou acetonitrila, e uma solução aquosa tamponada [4, 12, 18, 19, 26, 28]. A adição de par iônico à fase móvel foi utilizada apenas por DONG et al. [10] e OSSEYI et al. [20].

A detecção do ácido fólico é realizada por absorção na região do ultra-violeta $[15,20]$, enquanto que para os folatos, a preferência é utilizar a fluorescência $[12,14$, $27,28]$. Alguns autores utilizaram esses dois detectores em série para a determinação simultânea de AF e folatos $[13,16,26,27]$. CATHARINO \& GODOY [6] observaram que para concentrações baixas de ácido fólico $( \pm 20 \mu \mathrm{g} /$ $100 g)$ é possivel a detecção utilizando o detector de fluorescência, porém nenhum sinal foi registrado com concentrações maiores.

A identificação dos folatos, na maioria dos trabalhos publicados foi feita apenas por comparação com o tempo de retenção dos padrões e por co-cromatografia [4, 12, $18,19,20,26,28]$. KONINGS [16] utilizou para a identificação os espectros de absorção fornecidos pelo detector de arranjo de diodos. A quantificação foi feita por padronização externa $[4,12,16,18,19,20,26,28]$.

Este trabalho foi conduzido com o objetivo de avaliar algumas etapas analiticas para a determinação de ácido fólico, por CLAE, em leites enriquecidos, visando conhecer melhor o efeito de alguns parâmetros nessa determinação.

\section{2 - MATERIAL E MÉTODOS}

\section{1 - Material}

A amostra de leite em pó enriquecida com ácido fólico foi adquirida em supermercado da cidade de Campinas, SP.

O padrão de ácido fólico foi cedido pela M. CASSAB Comércio e Indústria LTDA., Santo Amaro, SP, Brasil. (SIGMA cód. F-7876, lote 40H321). Acetonitrila e metanol, ambos grau cromatográfico. Ácido tricloroacético, fosfato de potássio monobásico, ácido acético glacial, ácido fosfórico, grau de pureza analítico, foram adquiridos da Merck, Brasil. Da Synty foram utilizados o acetato de sódio e sódio fosfato dibásico anidro, grau de pureza analítico, e da SIGMA Chemicals Co (USA) o fosfato de potássio dibásico. A água utilizada no preparo das fases móveis foi purificada no sistema Milli-Q (MILLIPORE). As fases móveis foram filtradas em filtros fluoropore (FHLP 04700 MILLIPORE), com poros de $0,45 \mu \mathrm{m}$ de diâmetro. Foi utili-

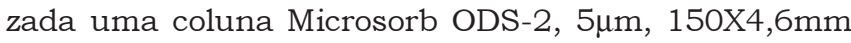
d.i.(Rainin Instrument Company), protegida por coluna de guarda Bondesil, $5 \mu \mathrm{m}, 10 \mathrm{X} 4,6 \mathrm{~mm}$ d.i. (Varian).

O equipamento utilizado foi um cromatógrafo a líquido HP (HEWELETT-PACKARD) modelo 1100, com desgaseificador, bomba quaternária, sistema de injeção automática (0 a $100 \mu \mathrm{L}$ ), detectores de UV-Visivel com arranjo de diodos e de fluorescência. Todo o sistema é controlado pelo programa HP-Chemstation, que também gerencia o sistema de aquisição e tratamento de dados.

\section{2 - Métodos}

\subsection{1 - Avaliação da composição da fase móvel e sistema de eluição}

A composição da fase móvel foi avaliada verificando-se a influência da presença de cada reagente, ou de variações nas concentrações dos mesmos, em sistemas de eluição isocrática e por gradiente, sobre soluções padrão de $\mathrm{AF}$ e amostra de leite em pó enriquecido. Os modificadores orgânicos, metanol e acetonitrila, foram testados em diferentes concentrações, mantendo-se constantes os outros componentes da fase móvel. A influência dos tampões fosfato e acetato, como componentes da fase móvel, também foi avaliada, assim como a influência do $\mathrm{pH}$. Neste caso, os valores foram ajustados com a adição de $\mathrm{HCl}(1 \mathrm{~mol} / \mathrm{L})$ e $\mathrm{KOH}(1 \mathrm{~mol} / \mathrm{L})$. A Tabela 1 resume todas as fases móveis e sistemas de eluição utilizadas neste trabalho.

\subsection{2 - Avaliação dos processos de limpeza do ex- trato e de extração}

Para a avaliação dos procedimentos de clarificação do extrato, este foi preparado com 1,0g de leite em pó enriquecido e o AF extraído com $3 \mathrm{~mL}$ de $\mathrm{KOH}(0,1 \mathrm{~mol} / \mathrm{L})$ em banho ultra-sônico por 10 minutos e, imediatamente após, foi submetido aos procedimentos de clarificação, apresentados a seguir. Os mesmos procedimentos foram repetidos paralelamente com soluções padrão de ácido fólico.

(a) extrato $+\mathrm{H}_{3} \mathrm{PO}_{4}(0,1 \mathrm{~mol} / \mathrm{L})$ qsp $10 \mathrm{~mL}$

(b) extrato + etanol qsp $10 \mathrm{~mL}$

(c) extrato + acetonitrila qsp $10 \mathrm{~mL}$

(d) extrato $+3 \mathrm{~mL}$ de $\mathrm{H}_{3} \mathrm{PO}_{4}(0,1 \mathrm{~mol} / \mathrm{L})+$ tampão fosfato $\mathrm{Na}_{2} \mathrm{HPO}_{4}(0,25 \mathrm{~mol} / \mathrm{L}) / \mathrm{KH}_{2} \mathrm{PO}_{4}(0,37 \mathrm{~mol} / \mathrm{L}) \mathrm{qsp} 10 \mathrm{~mL}$

(e) extrato $+3 \mathrm{~mL}$ de $\mathrm{H}_{3} \mathrm{PO}_{4}(0,1 \mathrm{~mol} / \mathrm{L})+350 \mu \mathrm{L}$ de ác. tricloroacético + tampão fosfato $\mathrm{Na}_{2} \mathrm{HPO}_{4}(0,25 \mathrm{~mol} /$ $\mathrm{L}) / \mathrm{KH}_{2} \mathrm{PO}_{4}(0,37 \mathrm{~mol} / \mathrm{L}) \mathrm{qsp} 10 \mathrm{~mL}$

Após os tratamentos, os extratos foram filtrados em membrana durapore (HVLP, 01300, MILLIPORE), com poros de $0,45 \mu \mathrm{m}$, e injetados no cromatógrafo, utilizando as melhores condições obtidas no item 2.2.1.

A extração foi realizada em duplicata, com 1,0g de leite em pó enriquecido. Todos os procedimentos foram conduzidos a temperatura ambiente $\left(27^{\circ}-30^{\circ} \mathrm{C}\right)$. Em todas as situações foram utilizados $3 \mathrm{~mL}$ de solução extratora, que permaneceram em contato com a amostra sem- 
pre por 10 minutos, com ou sem a utilização de banho ultra-sônico.

TABELA 1. Composição das fases móveis nos sistemas de eluição utilizados para a determinação da ácido fólico em leite.

\begin{tabular}{|c|c|c|c|}
\hline \multicolumn{4}{|c|}{ Sistema de Eluição Isocrático } \\
\hline Fase móvel & $(\mathrm{v} / \mathrm{v})$ & tr (min) & tc (min) \\
\hline Água & & - & 30 \\
\hline Metanol & & - & 30 \\
\hline Acetonitrila & & - & 30 \\
\hline Água/ Metanol & $10: 90$ & - & 30 \\
\hline Água/ Metanol & $15: 85$ & - & 30 \\
\hline Água/ Metanol & $30: 70$ & - & 30 \\
\hline Água/ Acetonitrila & 10:90 & - & 30 \\
\hline Água/ Acetonitrila & $12: 88$ & - & 30 \\
\hline Água/ Acetonitrila & $20: 80$ & - & 30 \\
\hline Tampão fosfato & & - & 30 \\
\hline Tampão acetato & & - & 30 \\
\hline Tampão fosfatol Metanol & $90: 10$ & 20 & 30 \\
\hline Tampão fosfato/ Metanol & $85: 15$ & 15 & 20 \\
\hline Tampão fosfato/ Metanol & $75: 25$ & 8 & 15 \\
\hline Tampão fosfato/ Metanol & $70: 30$ & 6 & 10 \\
\hline Tampão fosfatol Metanol & $65: 35$ & 5 & 10 \\
\hline Tampão fosfato/ Acetonitrila & $95: 5$ & 15 & 20 \\
\hline Tampão fosfato/ Acetonitrila & $90: 10$ & 8,5 & 15 \\
\hline Tampão fosfato/ Acetonitrila & $88: 12$ & 7,5 & 15 \\
\hline Tampão fosfato/ Acetonitrila & $85: 15$ & 7,4 & 15 \\
\hline Tampão fosfato/ Acetonitrila & $80: 20$ & 3,5 & 10 \\
\hline Tampão fosfato/ Acetonitrila & $78: 22$ & 3,4 & 10 \\
\hline Tampão fosfato/ Acetonitrila & $76: 24$ & 2,5 & 10 \\
\hline Tampão acetato/ Metanol & $90: 10$ & 20,4 & 30 \\
\hline Tampão acetato / Metanol & $85: 15$ & 14,9 & 20 \\
\hline Tampão acetato / Metanol & $75: 25$ & 8,1 & 15 \\
\hline Tampão acetato / Metanol & $70: 30$ & 6,2 & 10 \\
\hline Tampão acetato / Metanol & $65: 35$ & 4,8 & 10 \\
\hline Tampão acetato / Acetonitrila & $95: 5$ & 15 & 20 \\
\hline Tampão acetato / Acetonitrila & $90: 10$ & 8,4 & 15 \\
\hline Tampão acetato / Acetonitrila & $88: 12$ & 7,7 & 15 \\
\hline Tampão acetato / Acetonitrila & $85: 15$ & 7,3 & 15 \\
\hline Tampão acetato / Acetonitrila & $80: 20$ & 3,2 & 5 \\
\hline Tampão acetato / Acetonitrila & $78: 22$ & 3,1 & 5 \\
\hline Tampão acetato / Acetonitrila & $76: 24$ & 2,2 & 5 \\
\hline \multicolumn{4}{|c|}{ Siste ma de Eluição por Gradiente } \\
\hline Tampão acetato / Acetonitrila (v/v) & & tr (min) & te $(\min )$ \\
\hline Início $90: 10$ chegando a $76: 24$ em 4 & 4,5 & 5,5 & 6 \\
\hline Início 90:10 chegando a $76: 24$ em 5 & 5,5 & 5,8 & 6,5 \\
\hline Início $90: 10$ chegando a $76: 24 \mathrm{em} 7$ & 7,5 & 7,3 & 8 \\
\hline Início $90: 10$ chegando a $76: 24 \mathrm{em} 8$ & 8,5 & 8,3 & 9 \\
\hline Início $90: 10$ chegando a $76: 24 \mathrm{em} 9$ & 9,0 & 8,4 & 9 \\
\hline Início $90: 10$ chegando a $76: 24 \mathrm{em} 1$ & 10,5 & 8,7 & 11 \\
\hline Início $90: 10$ chegando a $76: 24 \mathrm{em} \quad 1$ & 11,5 & 8,9 & 12 \\
\hline Início $90: 10$ chegando a $76: 24 \mathrm{em} 1$ & 12,0 & 9 & 12,5 \\
\hline Início $90: 10$ chegando a $76: 24 \mathrm{em} 1$ & 15,0 & 9,1 & 15,5 \\
\hline Início 90:10 chegando a 76:24 em 1 & 16,0 & 9,3 & 16,5 \\
\hline Início $90: 10$ chegando a $76: 24 \mathrm{em} \quad 1$ & 17,0 & 9,3 & 17,5 \\
\hline
\end{tabular}

tr- tempo de retenção do ácido fólico; tc- tempo de corrida; - AF não eluiu durante a corrida.

Foram testados alguns solventes e várias soluções, desde água até soluções ácidas e tampões. A composição das soluções é descrita em anexo aos resultados apresentados (Tabela 2).

\subsection{3 - Detecção e identificação}

Os picos foram detectados, através de detector de arranjo de diodos (DAD), em quatro diferentes comprimentos de onda, 280, 285, 290 e 295nm, bem como no detector de fluorescência (excitação a $280 \mathrm{~nm}$ e $360 \mathrm{~nm}$ de emissão), ligado em série. A identificação foi feita por comparação dos tempos de retenção obtidos com padrões analisados nas mesmas condições, por co-cromatografia e pelos espectros de absorção obtidos nos dois detectores. O grau de pureza do pico referente ao ácido fólico foi avaliado pelos espectros de pureza e pelo sistema de plotter, fornecidos pelo programa HP-Chemistation.

\subsection{4 - Avaliação da estabilidade do padrão}

A curva analitica de padronização externa foi construída com 1, 2, 3, 4, 5, 6 e 7mL e uma solução padrão contendo $100 \mu \mathrm{g} / 100 \mathrm{~mL}$ de ácido fólico. As aliquotas foram diluídas para $10 \mathrm{~mL}$ com tampão fosfato $\mathrm{Na}_{2} \mathrm{HPO}_{4}$ $(0,25 \mathrm{~mol} / \mathrm{L}) / \mathrm{KH}_{2} \mathrm{PO}_{4}(0,37 \mathrm{~mol} / \mathrm{L})$. As soluções foram filtradas em membrana durapore (HVLP 01300 MILLIPORE) e injetadas no cromatógrafo, utilizando as melhores condições obtidas no item 2.2.1.

A estabilidade do padrão de AF foi avaliada variando-se algumas condições tais como:

- $\quad$ substância escolhida para dissolução do padrão: água e tampão fosfato.

- $\quad$ exposição à luz fria do laboratório por 20, 30 e 60 minutos.

- exposição a diferentes temperaturas de $25^{\circ}$ a $70^{\circ} \mathrm{C}$.

Após os tratamentos as soluções foram imediatamente injetadas no cromatógrafo, nas mesmas condições utilizadas anteriormente.

\section{3 - RESULTADOS E DISCUSSÃO}

\section{1 - AValiação dos parâmetros cromatográficos}

\subsection{1 - Fase móvel e sistema de eluição}

Fases móveis compostas apenas por água, tampão acetato $(0,166 \mathrm{~mol} / \mathrm{L})$ ou tampão fosfato $(0,33 \mathrm{~mol} / \mathrm{L})$ não foram suficientes para eluir o padrão de ácido fólico, surgindo a necessidade da adição de um modificador orgânico. A adição de acetonitrila $(\mathrm{ACN})$ ou metanol $(\mathrm{MEOH})$ em água pura não apresentou nenhum efeito. Já a adição desses modificadores, mesmo em concentrações baixas, nos dois tampões estudados resultaram na eluição do AF. Porém, para uma eluição mais rápida necessitou-se de concentrações maiores desses solventes orgânicos (Figura 1), sendo que a acetonitrila provocou maior influência na retenção da vitamina, por unidade de concentração na fase móvel, do que o metanol. A utilização de metanol, na fase móvel, aumentou significativamente o ruído da linha de base, portanto, foi dada preferência à utilização de ACN.
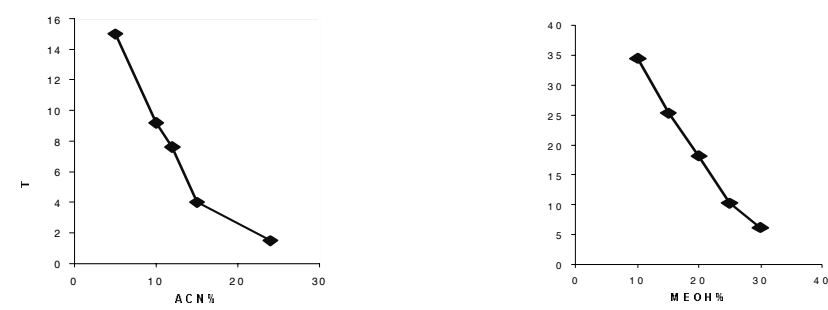

FIGURA 1. Efeito da concentração dos modificadores orgânicos na retenção do ácido fólico. Coluna Microsorb, ODS-2, $5 \mu \mathrm{m}$ 150X4,6mm. (1)Fase móvel: acetonitrila, solução tampão acetato ou fosfato, $\mathrm{pH} 2,8$, vazão de $0,5 \mathrm{~mL} / \mathrm{min}$. (2)Fase móvel: metanol, solução tampão acetato ou fosfato, $\mathrm{pH} 2,8$, vazão de $0,5 \mathrm{~mL} / \mathrm{min}$. 
Em conseqüência da obtenção de resultados semelhantes com a utilização de acetato ou fosfato, deu-se preferência ao acetato em virtude da possibilidade de cristalização do fosfato e, a degeneração de coluna causada por este tampão.

Os mesmos testes foram feitos com amostras de leite em pó enriquecidas, e as melhores condições foram obtidas com $10 \%$ de ACN em tampão acetato, que permitiu a eluição do AF em aproximadamente 8,0 minutos, a uma vazão de $0,5 \mathrm{~mL} / \mathrm{min}$, entretanto sempre havia a presença de um co-eluente, que só pode ser visto com o auxilo do sistema plotter da Chemistation-HP.

Foi observado o efeito do $\mathrm{pH}$ na retenção do ácido fólico (Figura 2), nas melhores condições cromatográficas até então estabelecidas. Maior retenção foi obtida numa faixa de $\mathrm{pH}$ muito próxima ao valor do $\mathrm{pK} 1(3,1)$ do ácido fólico.

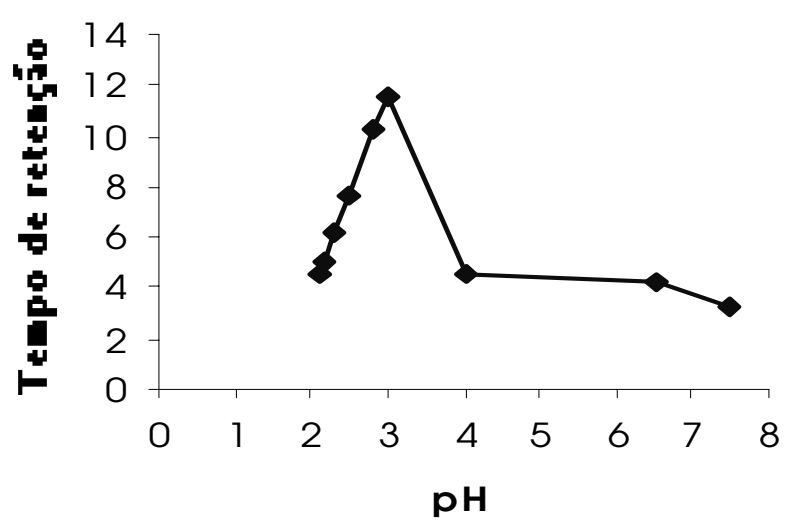

FIGURA 2. Efeito da concentração hidrogeniônica na retenção

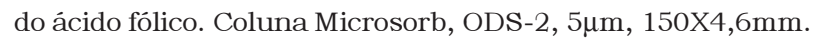
Fase móvel: acetonitrila 10\%, em solução tampão acetato, com vazão de $0,5 \mathrm{~mL} / \mathrm{min}$.

O sistema de eluição isocrático, mesmo com todas as otimizações feitas em relação a fase móvel, nas amostras de leites enriquecidos com AF não se mostrou satisfatório, levando a estudos com sistemas de eluições por gradiente.

De todos os gradientes utilizados (Tabela 1), o me1hor sistema foi formado com 10\% de acetonitrila e $90 \%$ de fase aquosa tamponada (ácido acético 0,166mol/L; hidróxido de potássio $0,01 \mathrm{~mol} / \mathrm{L} ; \mathrm{pH} \mathrm{2,8)} \mathrm{no} \mathrm{início} \mathrm{da}$ corrida, chegando a oito minutos e meio $(8,5 \mathrm{~min}) \mathrm{com}$ $24 \%$ de acetonitrila e $76 \%$ de fase aquosa tamponada, permanecendo estas condições até nove minutos ( $9 \mathrm{~min})$ de corrida, quando as condições cromatográficas iniciais eram retomadas. A baixa concentração do modificador orgânico no início da corrida, programado para um aumento linear na concentração de solventes, favoreceu a boa resolução da vitamina em relação a compostos interferentes da matriz alimentícia, além de possibilitar uma corrida mais rápida do que as existentes na literatura. Após vários ensaios, foi estabelecido o tempo de 5 minutos para o re-equilibrio da coluna.

\section{2 - Avaliação dos procedimentos de limpeza do ex- trato e de extração}

Em decorrência das características da matriz, os procedimentos de clarificação do extrato foram conduzidos com a finalidade da eliminação, principalmente, de proteínas.

O emprego de ácido fosfórico $0,1 \mathrm{~mol} / \mathrm{L}$ resultou num extrato demasiadamente sujo, ocasionando elevação da pressão e rápido entupimento da coluna. O mesmo ocorreu quando combinado o ácido fosfórico com uma solução concentrada de sais $\left(0,25 \mathrm{~mol} / \mathrm{L} \mathrm{Na}_{2} \mathrm{HPO}_{4}+0,37 \mathrm{~mol} /\right.$ $\mathrm{L} \mathrm{KH}_{2} \mathrm{PO}_{4}$ ). Etanol e acetonitrila, para a limpeza do extrato, também não foram satisfatórios.

A adição de ácido tricloroacético concentrado à mistura de ácido fosfórico e solução salina apresentou-se como uma medida prática e eficiente de clarificação do extrato.

Em virtude de se trabalhar com produtos enriquecidos, a hidrólise enzimática, empregada na grande maioria dos trabalhos da literatura, se mostrou desnecessária, já que nos produtos analisados neste trabalho a vitamina se encontra na forma monoglutâmica livre. Muitas vezes, como resultado da hidrólise da matriz alimentícia, há a liberação de mais interferentes que dificultam tanto a análise qualitativa como quantitativa [1].

Avaliou-se a influência do banho ultra-sônico na extração do ácido fólico em leite em pó enriquecido em comparação à simples agitação mecânica (Tabela 2). As taxas de recuperação foram signitivamente maiores com a utilização do banho ultra-sônico por 10 minutos, com todas as soluções extratoras. O prolongamento do tempo de extração, com o uso do ultra-som, promoveu a redução nos teores de ácido fólico.

TABELA 2. Comparação das taxas de recuperação do ácido fólico obtidas com diferentes soluções extratoras, sem e como o

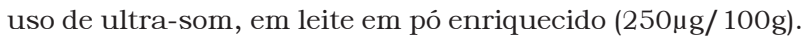

\begin{tabular}{|c|c|c|}
\hline \multirow[b]{2}{*}{ Solucões extratoras* } & \multicolumn{2}{|c|}{ recuperação $(\%)^{* * *}$} \\
\hline & sem ultra-som & com ultra-som \\
\hline Água & $26 \pm 1 \mathrm{a}$ & $55 \pm 2 \mathrm{~b}$ \\
\hline Metanol & $21 \pm 2 \mathrm{a}$ & $52 \pm 1 \mathrm{~b}$ \\
\hline Acetonitrila & $23 \pm 2 \mathrm{a}$ & $52 \pm 1 \mathrm{~b}$ \\
\hline Tampão fosfato $(0,03 \mathrm{~mol} / \mathrm{L}) \mathrm{pH} 2,5$ & $15 \pm 2 \mathrm{a}$ & $45 \pm 2 b$ \\
\hline Tampão fosfato $(0,03 \mathrm{~mol} / \mathrm{L}) \mathrm{pH} 5$ & $35 \pm 1 \mathrm{a}$ & $60 \pm 1 \mathrm{~b}$ \\
\hline Tampão fosfato $(0,03 \mathrm{~mol} / \mathrm{L}) \mathrm{pH} 6,5$ & $43 \pm 1$ a & $85,1 \pm 0,8 \mathrm{~b}$ \\
\hline Tampão fosfato $(0,03 \mathrm{~mol} / \mathrm{L}) \mathrm{pH} 7$ & $51 \pm 1 \mathrm{a}$ & $87,5 \pm 0,7 \mathrm{~b}$ \\
\hline $\mathrm{K}_{2} \mathrm{HPO}_{4}(0,03 \mathrm{~mol} / \mathrm{L}) \quad \mathrm{pH} 8$ & $88,8 \pm 0,8 \mathrm{a}$ & $98,5 \pm 0,1 \mathrm{~b}$ \\
\hline $\mathrm{KOH}(0,1 \mathrm{~mol} / \mathrm{L})$ & $88,3 \pm 0,7 \mathrm{a}$ & $99 \pm 0,5 \mathrm{~b}$ \\
\hline Tampão acetato $(0,1 \mathrm{~mol} / \mathrm{L}) \mathrm{pH} 2,5$ & $20 \pm 1$ a & $50 \pm 1 \mathrm{~b}$ \\
\hline Tampão acetato $(0,1 \mathrm{~mol} / \mathrm{L}) \mathrm{pH} 5$ & $25 \pm 1$ a & $65 \pm 1 \mathrm{~b}$ \\
\hline Tampão acetato $(0,1 \mathrm{~mol} / \mathrm{L}) \mathrm{pH} 6,5$ & $47 \pm 1 \mathrm{a}$ & $87,6 \pm 0,7 \mathrm{~b}$ \\
\hline Tampão acetato $(0,1 \mathrm{~mol} / \mathrm{L}) \mathrm{pH} 7$ & $52 \pm 2 \mathrm{a}$ & $90,6 \pm 0,6 \mathrm{~b}$ \\
\hline $\mathrm{KOH}(0,1 \mathrm{~mol} / \mathrm{L})+$ Acetonitrila $(3: 1)$ & $85,3 \pm 0,7 \mathrm{a}$ & $98,5 \pm 0,6 \mathrm{~b}$ \\
\hline $\mathrm{KOH}(0,1 \mathrm{~mol} / \mathrm{L})+\operatorname{Met} a n o l(3: 1)$ & $85,2 \pm 0,8 \mathrm{a}$ & $98,4 \pm 0,6 \mathrm{~b}$ \\
\hline
\end{tabular}

*Todas soluções ficaram em contato com a amostra por 10minutos, sem e com banho ultra-sônico; ** média e estimativa de desvio padrão de determinações em duplicata;
Letras diferentes na mesma linha indicam diferença significativa ao nivel de $95 \%$

As menores taxas de recuperação com o uso do ultrasom (45 a 65\%) foram obtidas em meio ácido ou com a utilização de solventes puros. Tais condições promoveram a degradação do AF e/ou a extração parcial do mesmo. Em soluções com pH acima de 6,5, a porcentagem de recuperação chegou a $98,5 \%$ e $98,7 \%$ com as soluções de $\mathrm{K}_{2} \mathrm{PO}_{4}(0,03 \mathrm{~mol} / \mathrm{L})$ e $\mathrm{KOH}(0,1 \mathrm{~mol} / \mathrm{L})$, respecti- 
vamente. A adição de acetonitrila ou metanol, na proporção $1: 3$, na solução de $\mathrm{KOH}(0,1 \mathrm{~mol} / \mathrm{L})$ também possibilitou as mesmas altas taxas de recuperação $(98,5 \%)$.

\section{3 - Avaliação dos procedimentos de detecção e iden- tificação}

Embora na literatura exista um consenso em utilizar 280nm ( $\lambda$ máx) para a detecção do ácido fólico [5, 20, $23,29]$ foram avaliados neste trabalho, quatro diferentes comprimentos de onda, 280, 285, 290 e 295nm.
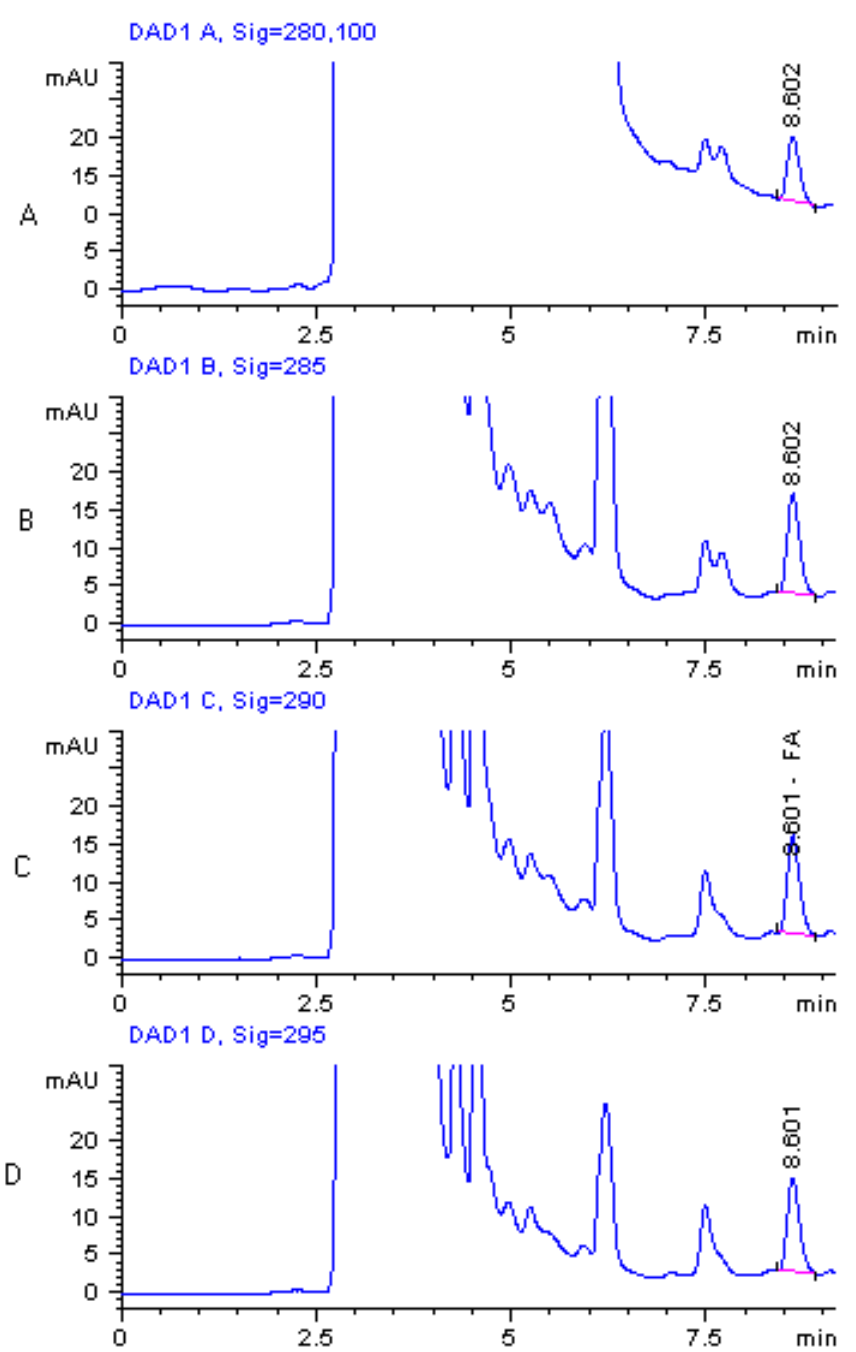

FIGURA 3. Perfis cromatográficos de extrato de leite em pó enriquecido com ácido fólico (AF), monitorados a diferentes comprimentos de onda: (A) 280nm: (B) 285nm; (C) 290nm;

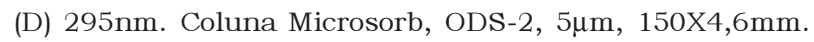
Fase móvel: $10 \%$ de acetonitrila e $90 \%$ de tampão acetato (0166mol/L)no início da corrida, chegando em 8,5 minutos a $76 \%$ de tampão acetato (0166mol/L) e 24\% de acetonitrila (v/v), mantendo-se nessas condições até 9,0 minutos. Vazão de $0,5 \mathrm{~mL} /$ minuto.

Utilizando o comprimento de onda de $280 \mathrm{~nm}$, observou-se que o pico referente ao ácido fólico, nas amostras de leite em pó, se posiciona exatamente na cauda de um interferente (Figura 3A). Porém, em comprimentos de onda acima de $280 \mathrm{~nm}$ há uma menor absorção dos compostos do extrato, com o desaparacimento da cauda desse interferente, sem contudo prejudicar a quantificação do AF (Figuras 3B, 3C e 3D). Obteve-se cromatogramas mais limpos, e como não houve diferença significativa nas áreas do pico do AF a 285, 290 e 295nm, foi estabelecida a detecção a 290nm, já que a 295nm a área do pico foi menor.

RUGGERI et al. [22] e VATHERISTO et al. [27] também estabeleceram o comprimento de onda para leitura de folatos a 290nm para amostras de cereais, salame, grão-de-bico e feijão, provavelmente pela forte interferência de matriz alimentícia.

Nos trabalhos encontrados na literatura os autores só apresentam a detecção por fluorescência para folatos, no entanto, quando se preparou uma solução de AF $(100 \mu \mathrm{g} / \mathrm{mL})$ obteve-se através de um fluorimetro o espectro de fluorescência, e portanto foi utilizada também essa propriedade para confirmação da identidade do AF, além do tempo de retenção e do espectro obtido no DAD. Foram estabelecidos os comprimentos de excitação e emissão a 280nm e 360nm, respectivamente, no detector de fluorescência (FLD). Entretanto, quando no extrato da amostra a concentração de AF era superior a $20 \mu \mathrm{g} /$ $\mathrm{mL}$, perdia-se o sinal do FLD.

\section{4 - Avaliação da estabilidade do padrão}

Depois de estabelecida a faixa de linearidade entre a área do pico e a concentração, através de padronização externa, o cálculo da concentração do AF presente nas amostras foi feito injetando-se todos os dias um dos pontos da curva. Portanto, para esse procedimento tornouse indispensável a avaliação da estabilidade da solução padrão de AF. Foram realizados testes de estabilidade frente as condições de temperatura, luz e solvente ao qual o padrão foi dissolvido.

As duas variáveis, temperatura e luz, não tiveram nenhum efeito negativo sobre a concentração do ácido fólico.O fator que mais influenciou na estabilidade do padrão foi o solvente. Mantidas a temperatura de geladeira $\left(4^{\circ} \mathrm{C}\right)$, soluções padrão de $\mathrm{AF}$ em tampão fosfato $(\mathrm{pH}$ $6,5)$ apresentaram uma estabilidade de 30 dias, enquanto que em água (pH 7,0) foi de apenas 1 dia (Figura 4).

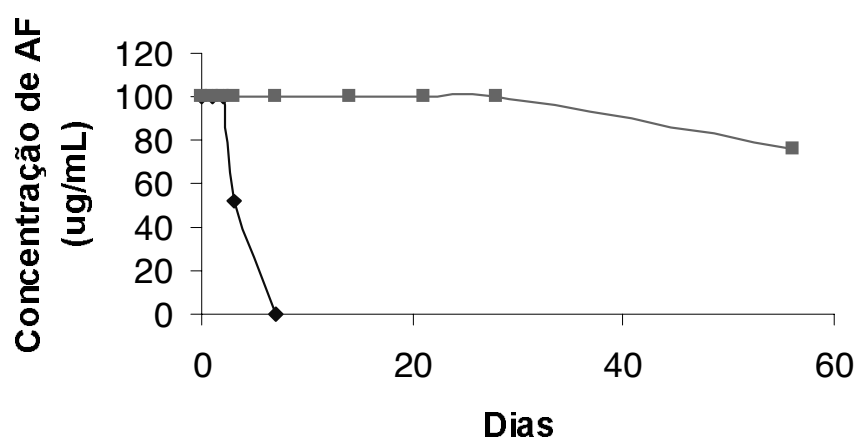

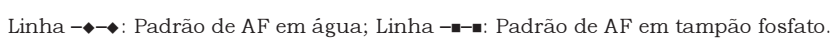

FIGURA 4. Estabilidade do padrão de AF em diferentes soluções. 


\section{4 - CONCLUSÕES}

- A extração com solução alcalina (KOH 0,1 mol/L), com vibração ultra-sônica por 10 minutos, apresentou-se como uma alternativa adequada na determinação de ácido fólico em leite em pó enriquecido, assim como o ácido tricloroacético se mostrou eficiente na etapa de limpeza do extrato.

- A eluição por sistema gradiente foi necessária para separar o ácido fólico de um co-eluente presente no leite em pó, e assim tornou mais rápida a análise.

- O sistema de detecção recomendado é através do detector de ultra-violeta a 290nm, para leites enriquecidos, devido à diminuição da interferência de outros constituintes da amostra.

- O padrão de ácido fólico se manteve estável por 30 dias em solução de tampão fosfato $(\mathrm{pH} \mathrm{6,5)} \mathrm{a}$ temperatura de refrigeração $\left(4^{\circ} \mathrm{C}\right)$. No entanto sugere-se um estudo multivariado mais abrangente sobre a estabilidade do padrão de ácido fólico.

- Alterações no pH e nas concentrações de acetonitrila ou metanol constituem as variações de primeira escolha na composição da fase móvel, para determinação do $\mathrm{AF}$ em outros produtos.

\section{5 - REFERÊNCIAS BIBLIOGRÁFICAS}

[1] Agostini, T.S.; GODOY, H.T. Simultaneous determination of nicotinic acid, nicotinamide, riboflavin, thiamin and pyridoxine in enriched Brazilian foods, by HPLC. Journal High resolution Chromatography, v. 20, n. 4, p. 3081-3086, 1997.

[2] ANNOTATION, United States of America. International Digies of Health Legislation, v. 47, n. 3, USA 96.39 e 96.40, 1996.

[3] ANNOTATION. How do we get ennough folic acid to prevent some neural tube defects. American Journal of Public Health, v. 84/3, p. 348-350, 1994.

[4] BERG, H.V.; Finglas P.M.; BATES, C. Flair intercomparisons on serum and red cell folate. International Journal Vitamins Nutrition, v. 64. p. 288-293, 1994.

[5] BRANFMAN, A.R.; MCCOMISH, M. Rapid separation of folic acid derivates by paired-ion high-performace liquid chromatography. Journal of Chromatography. v. 151. p 87-89, 1978.

[6] CATHARINO, R.R.; GODOY H.T. Desenvolvimento, validação e aplicação de metodologia para análise de ácido fólico em alimentos enriquecidos (dados não publicados), 2000.

[7] CRANE, N. T.; WILSON, D.B.; COOK, D.A.; LEWIS, C.J.; YETLEY, E.A.; RADER, J.I. Evaluating food fortification options: general principles revisited with folic acid. American Journal of Public Health, v. 85, n. 5, p. 660-666, 1995.

[8] CZEIZE, A.E.; DUDAS, I. Prevention of the first occurrence of neural tube defects by perioconceptional vitamin supplementetion. New England Journal of Medicine, v. 327, n. 26, p. 1832-1835, 1992.
[9] DALY, S.; MILls, JR.; MOLlOY, A.M.; CONLEY, M.; LEE, Y.J.; KIRKE, P.N.; WEIR, D.G.; SCOTT, J.M. Minimum effective dose of folic acid for food fortification to prevent neural-tube defects. Lancet, v. 350, n. 9092, p. 1666-1669, 1997.

[10] DONG, M.W; LEPORE, J; TARUMOTO, T. Factors affecting the ion-pair chromatography of watersoluble vitamins. Journal of Chromatography, v. 442, p 81-95, 1988.

[11] DUFF, E.M.W.; COOPER, E. Neural tube defects in Jamaica following hurricane gilbert. American Journal of Public Health, v. 84, n. 3, p. 473-475, 1994.

[12] FARRAR, G.; BUSS, D.H.; LOUGHRIDGE, J.; LEEMING, R. J.; HUGHES, K.; BLAIR, J. A. Food folates and the British total diet study. Journal Hum. Nutr.Diabetics, v. 5, p. 237-249, 1992.

[13] Finglas, P. M.; WIGERTZ, K.; VAHTERISTO, L.; WITTHÖFT, C.; SOUTHON, S.; FROIDMONTGÖRTZ, I. Standardisation of HPLC techniques for the determination of naturally-occurring folates in food. Food Chemistry. 64: 245-255, 1999.GREGORY, J.F.; SARTAIN, D.B. Inproved chromatographic determination of free and glycosylated forms of vitamins B6 in foods. Journal Agricututral Food Chemistry, v. 39, n. 1, p. 899-905, 1991.

[14] GREgORY III, J.F.; SARTAIN, D.B.; DAY, B.P. Fluorometric determination of folacin in biological materials using high performace liquid chromatography. Journal Nutrition, v. 114, p. 341353, 1984.

[15] HOLLMAN, P.C.; SLANGE, J.H.; WAGSTAFFE, J.P. ; FAURE, U.; SOUTHGATE, D.A.T.; FINGLAS, P.M. Intercomparation of methods for the determination of vitamins in food. Analyst, v. 118, p. 481-488, 1993.

[16] KONINGS, E.J.M. A validated liquid chromatographic method for determining folates in vegetables, milk powder, liver, and flour. Jounal of Association of Official Agricultural Chemists International. v. 82, n. 1, p. 119-127, 1999.

[17] LOCKSMiTH, G.J; DUFF, P. Preventing neural tube defects: The importance of periconceptional folic acid supplements. Obstrics \& Gynecology, v. 91, n. 6, p. 1027-1034, 1998.

[18] LUCOCK, M.D.; GREEN, M.; HARTLEY \& MALCOLM; LEVENE, I. Physicochemical and biological factors influencing methylfolate stability: use of dithiothreitol for HPLC analysis with electrochemical detection. Food Chemistry, v. 47, p. 79-86, 1993.

[19] LUCOCK, M.D.; GReEn, M.; PRIESTNALl, M.; DASKALAKIS, I.; LEVENE \& HARTLEY M.I. Optimisation of chromatographic conditions for the determination of folates in foods and biological tisues for nutritional and clinical work. Food Chemistry, v. 53, p. 329-338, 1995.

[20] OSSEYI, E.S.; WEHLING, R.L.; ALBRECHT, J.A. Liquid chromatographic method for determination added folic acid in fortified cereal products. Journal of Chromatography A. v. 826, n. 2, p. 235-240, 1998.

[21] RADER, J.I.; WEAVER, C.M.; AGYAL G.; Use of microbiological assay with tri-enzime extration for measurement of pre-fortification levels of folates in enriched cereal-grain products. Food Chemistry, v. 62, n. 4, p. 451-465, 1998. 
[22] RUGGERI, S.; VATHERISTO, L.T.; AGGUZZI, A.; FINGLAS, P.; CARNOVALE, E. Determination of folate vitamers in food and italian reference diet by high performace liquid chromatography. Journal of Chromatography v. 855, n. 1, p. 237-245, 1999.

[23] SCHULZ, A.; WEIDEMANN, K.; BITSCH, I. Stabilisation of $5-\mathrm{CH}_{3} \mathrm{H}_{4}$-Pglu and subsequent analysis by reverse phase high performace liquid chromatography. Journal of Chromatography, v. 328, p. 417-421, 1985.

[24] SERBANESCU, F; ROCHAT, R; FLOYD, V; TOOMEY, K.E. Knowledge about folic acid and use of multivitamins containing folic acid among reproductive-age women - Georgia 1995. Morbidity and Mortality Weekly Report, v. 45, n. 37 p. 793795, 1996.

[25] TAMURA, T.; MESSING, B. Bioavailability of folic acid in fortified food. Amarican Journal of Clinical Nutrition, v. 66, n. 6, p. 1299-1300, 1997.
[26] VAHTERISTO L.T, OLLILAINEN V.; KOIVISTOINEN, P.E.; VARO, P. Improvements in the analysis of reduced folate monoglutamates and folic acid in food by high-performace liquid chromatography. Journal Agriculture Food Chemistry v. 44, p. 477-482, 1996.

[27] VAHTERISTO, L.T.; OLLILAINEN, V.; VARO, P. Application of HPLC assay for the determination of folate derivatives in some vegetables, fruits and berries consumed in Finland, Food Chemistry, v. 59, n. 4 , p. 589-597, 1997.

[28] WIGERTZ, K.; JÄGERSTAD, K. Comparison of a HPLC and radioprotein-biding assay for the determination of folates in milk and blood samples, Food Chemistry, v. 54, n. 4 p. 429-436, 1995.

[29] WILLS, R.B.H.; SHAW, C.G.; DAY, W.R. Analysis of water soluble vitamins by high pressure liquid chromatography. Journal of Chromatography Science, v. 15, p. 262-266, 1977. 